\title{
The Advanced Activities of Daily Living: a tool allowing the evaluation of subtle functional decline in Mild Cognitive Impairment
}

Patricia De Vriendt 1, 3, 4 , Ellen Gorus ${ }^{1,2,4}$, Elise Cornelis ${ }^{2}$, Ivan Bautmans 1, 2, 4, Mirko Petrovic ${ }^{3,4}$, Tony Mets ${ }^{1,2,4}$

${ }^{1}$ Frailty in Ageing (FRIA) research group and Gerontology department, Faculty of Medicine and Pharmacy, Vrije Universiteit Brussel, Laarbeeklaan 103, 1090 Brussels, Belgium;

${ }^{2}$ Department of Geriatrics, Universitair Ziekenhuis Brussel, Laarbeeklaan 101, 1090 Brussels, Belgium;

${ }^{3}$ Department of Geriatrics, Ghent University Hospital, De Pintelaan, 185, 9000 Ghent, Belgium;

${ }^{4}$ Research in Gerontology and Geriatrics (REGG), Alliance Research group between FRIA, Gerontology and Geriatrics departments from the Vrije Universiteit Brussel \& Universitair Ziekenhuis Brussel, and Geriatrics department from Ghent University and Ghent University Hospital.

Key terms: International Classification of Functioning, Disability and Health; cognitive disorders; Alzheimer's disease; assessment of daily functioning; geriatric assessment

Running title: functional decline in MCI

\section{Abstract: \\ Objectives}

Assessment of advanced activities of daily living (a-ADL) can be of interest in establishing the diagnosis of Alzheimer's disease $(A D)$ in an earlier stage, since these activities demand high cognitive functioning and are more responsive to subtle changes. In this study we tested a new a-ADL tool, developed according to the International Classification of Functioning, Disability and Health (ICF). The a-ADL tool is based on the total number of activities performed (TNA) by a person and takes each subject as his own reference. It distinguishes a total Disability Index (a-ADL-DI), a Cognitive Disability Index (a-ADLCDI), and a Physical Disability Index (a-ADL-PDI), with lower score representing more independency. We explored whether these indices allow distinction between cognitively 
healthy persons, patients with Mild Cognitive Impairment (MCI) and patients with mild AD.

\section{Methods}

Participants were on average 80 years old (SD $4.6 ; 66-90$ ), were community dwelling, and were diagnosed as (1) cognitively healthy subjects $(n=26) ;(2)$ patients with MCI ( $n$ $=17)$, or (3) mild $A D(n=25)$, based upon extensive clinical evaluation and a set of global, cognitive, mood and functional assessments. The a-ADL-tool was not part of the clinical evaluation.

\section{Results}

The a-ADL-CDI was significantly different between the three groups $(p<.01)$. The a-ADLDI was significantly different between MCI and AD $(p<.001)$. The tool had good psychometrical properties (inter-rater reliability; agreement between patient and proxy; correlations with cognitive tests). Although the sample size was relatively small, ROC curves were computed for the a-ADL-DI and a-ADL-CDI with satisfactory and promising results.

\section{Conclusion}

The a-ADL-CDI and a-ADL-DI might offer a useful contribution to the identification and follow up of patients with mild cognitive disorders in an older population.

\section{Conflict of interest declaration: none}

\section{Acknowledgements:}

This study was partly supported by the LUNDBECK GERIATRIC MEDICINE GRANT, 2010, Belgium.

The authors are indebted to Sabrina Janssens, student at the Vrije Universiteit Brussel, Gerontology Department, and Soetkin Drieghe, student at the Artevelde University College, Occupational Therapy Department, for their valuable help in the study. 


\section{Introduction}

Mild Cognitive Impairment (MCI) has been defined as a condition of cognitive deterioration that is more pronounced than expected for age, but clearly not as severe as in dementia [1-3]. While activities of daily living (ADL) are most often impaired in dementia, they should remain relatively intact in MCI. Nevertheless, several studies have demonstrated subtle but obvious problems in MCI patients for more complex ADL [4-7]. Therefore, the extent of limitations in ADL is part of the diagnostic differentiation between normal cognitive ageing, MCI and dementia.

$A D L$ can be stratified according to difficulty and complexity in three levels of functioning [8]. Basic ADL ( $b-A D L)$ are defined as the activities meeting the basic physiological and self maintenance needs. Instrumental ADL (i-ADL) are essential, together with $b-A D L$, to maintain independent living. Advanced $A D L$ (a-ADL) are more sophisticated activities, beyond those necessary to live independently. When trying to establish the diagnosis of Alzheimer's disease (AD) in an early stage, assessment of a$A D L$ can be of great interest since these activities demand high cognitive functioning and are, therefore, more responsive to subtle changes [9-11]. However, at this moment it is still uncertain which domains of functioning may be impaired and to what extent. While b-ADL and $\mathrm{i}-\mathrm{ADL}$ tend to be rather stable across populations, a-ADL are highly culture and gender specific and influenced by personal choices, making them difficult to evaluate [8]. Moreover, it should be ascertained that a-ADL impairment is due to cognitive deficits, and not to co-morbidities and physical impairments, commonly present in older patients [2], or to social or environmental circumstances [12]. With the increased use of new technologies in housekeeping and other activities [13], there is a need for assessment tools with up-to-date items. Presently, the commonly used instruments often fail to capture the subtle impairments encountered in MCI. Although several relevant studies were carried out the past years [4, 11, 14-20], at this moment there are neither age-specific norms for levels of functioning, nor normal rates of functional decline available.

The on-going study reports on an up-to-date tool to evaluate a-ADL aiming to contribute to the identification of MCI. It was designed according to the International Classification of Functioning, Disability and Health (ICF), the leading framework and facilitator for clinical practice and research [12, 21-23]. Here we evaluate this new a-ADL tool for its (1) feasibility, (2) content validity, (3) reliability of the scoring system, (4) construct validity and (5) predictive validity.

\section{Participants and methods}




\section{Participants and data-collection}

Three groups of consecutive participants were recruited: (1) apparently cognitively healthy older persons, (2) patients with MCI and (3) patients with mild AD. All participants attended the geriatric day hospital at the Universitair Ziekenhuis Brussel or Ghent University Hospital, were 65 years of age or older, and community dwelling. Exclusion criteria were: any acute pathology, sensory or communicative impairments which precluded them from participating, and any other pathology of the central nervous system.

The study was approved by the local Ethical Committee of the involved hospitals and all patients gave written informed consent. All data were collected in accordance with the Declaration of Helsinki.

\section{Patients with MCI or $A D$}

Forty-two consecutive patients with a clinical diagnosis of MCI $(n=17)$ or mild AD ( $n=$ 25) were included. For the MCI group, the criteria as defined by the International Working Group on MCI [2] were used. The AD group met the criteria for dementia according to Diagnostic and Statistical Manual of Mental Disorders Forth version (DSM-IV) [24] or National Institute of Neurological and Communicative Disorders and Stroke and the Alzheimer's Disease and Related Disorders Association (NINCDS-ADRDA) [25]. All patients underwent a complete diagnostic procedure [26] and were evaluated with Mini Mental State Evaluation (MMSE) [27], Cambridge Examination for mental disorders of the elderly, Cognitive part (CamCog) [28], Geriatric Depression Scale (GDS) [29], Neuropsychiatric Inventory Questionnaire (NPI-Q) [30], b-ADL according to Katz et al. [31], (modified version, with scores expressed as percentage where 100\% represents complete dependency) and i-ADL according to Lawton et al. [32, 33], (a modified gender specific version, expressed as percentage where $100 \%$ represents complete dependency; for men a 6 item version (ability to use telephone, shopping, transportation, handling medication, handling finances an handyman work), for women a 8 item version (food preparation, housekeeping, laundry, ability to use telephone, shopping, transportation, handling medication and finances)), completed with a physical evaluation, inventory of co-morbidities and medication use, extensive laboratory blood testing and imaging of the brain (CT scan or MRI).

\section{Cognitively healthy older people}

The control group $(n=26)$ was a sample of apparently cognitively healthy volunteers recruited in the community. They were assessed with the same evaluation methods as 
the patients, except for the NPI-Q [30], extensive laboratory blood testing and imaging of the brain (CT scan or MRI). For their physical status, self-reports were used (comorbidities and medication use). Exclusion criteria were any objective functional or cognitive deficit which could be suggestive for the diagnosis of MCI or AD (MMSE $<25 / 30$; CamCog <80/105).

\section{Procedure}

For the patient groups, assessments were performed by the usual professional workers at the day hospitals. The a-ADL tool under investigation was not part of the diagnostic process and was carried out by trained investigators who were blinded for the results of the other tests and the diagnosis of the subject. Preferably, data should also be obtained from the proxies since in cognitive assessment, informant report is considered as reliable [14], but for study purposes, data were obtained from both patients and proxies in order to evaluate the agreement between them. In random order, assessments of patient and proxy were performed by the same assessor. The apparently cognitively healthy volunteers were evaluated by the researchers, for the a-ADL tool and for the other tests.

\section{The a-ADL measurement tool}

\section{Items of the a-ADL measurement tool}

The measurement tool (see table 1) encompasses 49 activities, divided in 15 clusters according to the ICF [12], which were identified in a previous qualitative study of functional decline in a population with MCI [34]. The tool takes into account that a-ADL are highly individual and offers the possibility to evaluate activities, other than the 49 key a-ADL, that subjects might report.

\section{Interview protocol}

To guarantee the standardization of the instrument, an instruction session (approximately 1 hour) was organized for all raters, during which the structured interview guide and the scoring system were presented and also some interview techniques were clarified (e.g. use eliciting probes to let participants elaborate on their performance). First, the subject and/or proxy is asked whether the activity was ever performed during the years preceding the present problems (we suggested by thinking back to the years before problems occur). In this way, each of the 49 items is rated for its relevance for the individual in question. The activity is considered relevant if it is currently performed or if it was performed previously. Next, the subject is asked how the activities that have been identified as relevant are performed and, the observer assigns a score. Finally, the underlying cause of limited performance is rated, based on this story. In this study, the assessment was done by occupational therapists, but it can also be 
administered by other health care workers with experience and knowledge on functionality in geriatrics.

\section{Scoring of the a-ADL items}

The rating system adopted the performance qualifiers of the ICF [12], a five-point scale, ranging from 0 (no difficulty to perform) to 4 (complete difficulty). Based on the results of the previous qualitative study [34], the qualifiers were operationalised (see table 2).

\section{Underlying causes of limited performance}

If performance scores are $>0$, the underlying reason (intrinsic or extrinsic) for the limitation is rated. Intrinsic factors are distinguished as cognitive (e.g. memory problems), intra-personal (e.g. switch in field of interest) or physical (e.g. mobility problems). The extrinsic factors are social (e.g. loss of partner) or environmental (e.g. car sold) reasons. It is possible to attribute more than one cause to the reported limitation in performance.

\section{Indices}

First, a 'global disability index' (a-ADL-DI) is calculated, taking into account the total number of activities (TNA) found relevant, the number of activities that are limited (LA) and the severity of the limitation (ICF scores). A 'cognitive disability index' (a-ADL-CDI) and 'physical disability index' (a-ADL-PDI) are computed, considering exclusively the activities that are limited because of respectively cognitive and physical problems. Activities in which the limitation is partly due to physical and partly due to cognitive reasons are included in both indices (a-ADL-CDI and a-ADL-PDI). As an example, the cognitive index reflects the proportion of limited activities due to cognitive reasons, multiplied by the severity of the limitations, relative to the TNA. The indices are expressed as percentages, with lower scores indicating less disability.

$$
\begin{aligned}
& \text { a-ADL-DI }=\left(1-\left(\frac{T N A * 4-\sum_{i=1}^{L A} \text { LimAct }_{i} * \text { ICFscoreAct }_{i}}{T N A * 4}\right)\right) * 100 \\
& \text { a-ADL-CDI }=\left(1-\left(\frac{T N A * 4-\sum_{i=1}^{L A} \operatorname{LimAct}_{i} * \text { ICFscoreAct } C_{i}}{T N A * 4}\right)\right) * 100
\end{aligned}
$$


a-ADL-PDI $=\left(1-\left(\frac{T N A * 4-\sum_{i=1}^{L A} \operatorname{LimAct}_{i} * \text { ICFscoreAct } P_{i}}{T N A * 4}\right)\right) * 100$

with LimAct $_{\mathrm{i}}=$ the $i$-th limited activity ( $C=$ cognitive, $\mathrm{P}=$ physical), ICFscoreAct $_{\mathrm{i}}=$ the ICF- $^{\text {the }}$ score corresponding to the $i$-th limited activity.

Example: a person previously performed 25 a-ADL activities (TNA-25). Score 0 is assigned to 5 of them, score 1 is assigned to 15 activities due to cognitive problems and score 4 is assigned to 5 other activities due to physical factors. This person's LA is 20 . His a-ADL-DI is $35 \%$ (all limited activities are taken into account), the a-ADL-CDI is $15 \%$ (only the activities limited due to cognitive reasons are taken into account) and the aADL-PDI is $20 \%$.

\section{Clinimetric properties}

Feasibility was checked by evaluating time use, transparency and comprehensibility in a sample of the first 30 subjects. Content validity was checked by calculating the prevalence of the reported a-ADL-items (expressed as a percentage) for the whole study group ( $N=68)$. The reliability of the scoring system was checked by (1) evaluating the agreement between patient and proxy for a-ADL-assessments of $11 \mathrm{MCI}$ and $16 \mathrm{AD}$ patients as they were present in the hospital (12 children, 12 partners, 3 missing), based on separate questioning of patient and the proxy; and by (2) assessing the inter-rater reliability by comparing the simultaneous observation of the a-ADL interview by two independent raters in a sample of 24 participants ( 11 healthy controls, 1 MCI patient, 6 $A D$ patients and 6 proxies). In the absence of a true golden standard, construct validity was checked by (1) calculating correlations between the a-ADL-indices and the scales reflecting cognitive functioning (MMSE and CamCog) ( $\mathrm{N}=68)$; we assumed that a-ADL-DI and a-ADL-CDI would show stronger relationships than a-ADL-PDI; and (2) evaluating differences between groups $(\mathrm{N}=68)$. We hypothesised for both indices that healthy persons would show less disability than people with MCI and the latest less than people with $A D$, but that the a-ADL-CDI would differ more than the a-ADL-DI. Predictive validity was evaluated by calculating the specificity and sensitivity for the indices $(N=68)$.

\section{Statistical analysis}

Statistical analyses were done using IBM SPSS statistics 19.0 (SPSS Inc, Illinois, USA). Data are reported as medians and interquartiles. Since most datasets were not-normally distributed (Kolmogorov-Smirnoff Goodness of Fit test $\mathrm{p}<.05$ ) or expressed on ordinal scales (b-ADL, i-ADL), non-parametric tests were used. 
Patient-proxy agreement and inter-rater reliability were evaluated by computing intra class correlation coefficients (ICC, model 2, 1). Confidence intervals of $95 \%$ are reported. The relationships between a-ADL indices and clinical outcomes were assessed using a Spearman's correlation coefficient. Differences between groups were tested by KruskalWallis, Mann-Whitney U, Wilcoxon Signed Ranks or Chi-square Test. ROC curves were computed for the predictive validity. Significance was set a priori at two sided $p<0.05$. We considered a significance of 0.05 until 0.10 as a tendency.

\section{Results}

\section{The participants}

Table 3 shows the characteristics of the participants. Twenty-three men and forty-five women were included; thirty-three participants were living alone; there were no significant differences for gender and housing state between the three groups. Significant differences between the groups were observed for education (higher in control and $A D$ compared to the MCI subjects); medication use (less in the control compared to MCI and AD subjects); co-morbidities (less in control than in AD); $\mathrm{i}-\mathrm{ADL}$ (the controls being more independent than the MCI and the AD group and the MCI group being more independent than the AD group); and b-ADL (the healthy control group was less dependent than the $A D$ group).

\section{Prevalence of a-ADL items and distribution of the limitation scores}

Table 1 shows the various a-ADL reported by the respondents. More than $50 \%$ of the participants reported at least 22 of the 49 a-ADL items as relevant. To play a music instrument was the activity with the lowest prevalence (4.4\%). No extra a-ADL other than the 49 included in the list were reported. In table 3 the distribution of ICF scores compared to respectively TNA (ICF 0 ) or LA (ICF 1-4) within the diagnostic groups is shown. Score 0 and 3 differed significantly between the AD group and the other groups and score 1 showed a significant difference between all groups.

\section{The indices}

The results for the indices are shown in table 3. Healthy controls performed more activities (TNA) than patients with $M C I$ or with $A D$; for patients with $M C I$ there was a tendency towards having more activities than AD patients $(p=.070)$. LA was significantly higher in $A D$ patients than in the healthy controls and in MCI patients. The a-ADL-DI showed a significant difference between the AD group and the healthy controls and $\mathrm{MCI}$ group; between healthy controls and MCI patients a tendency was observed $(p=.099)$. The a-ADL-CDI differed significantly between all groups with the healthy controls having 
a better score than the MCI patients and the latter better than the AD patients. The aADL-PDI showed no significant difference between the groups.

\section{Receiver Operating Characteristics Curves}

Although preliminary due to small sample size, ROC curves were computed for a-ADL-DI and a-ADL-CDI, but not for the a-ADL-PDI since no significant difference between the groups was shown. For the a-ADL-DI the optimal cut-off was $24.7 \%$ for distinguishing healthy controls from MCI yielding a sensitivity of $65 \%$ and a specificity of $62 \%$ (AUC .650); for MCI versus AD the optimal cut-off was $38.5 \%$ yielding a sensitivity of $96 \%$ and a specificity of $71 \%$ (AUC .854); the optimal cut-off was at $42.4 \%$ for distinguishing healthy controls from $A D$ yielding a sensitivity of $92 \%$ and a specificity of $92 \%$ (AUC .965). For the a-ADL-CDI the optimal cut-off was $16.5 \%$ for distinguishing healthy controls from MCI yielding a sensitivity of $71 \%$ and a specificity of $73 \%$ (AUC .724); for MCI versus AD the optimal cut-off was $32.8 \%$ yielding a sensitivity of $79 \%$ and a specificity of $71 \%$ (AUC.809); the optimal cut-off was $23.3 \%$ for distinguishing healthy controls from $A D$ yielding a sensitivity of $92 \%$ and a specificity of $100 \%$ (AUC .982).

\section{Time use and comprehensibility}

Questioning took on average $33 \pm 9$ minutes (range 15-50), with higher interview times in the AD-group $(p<.01)$. The investigators reported no problems with comprehensibility or tiredness of the subjects. All participants reported to have enjoyed the assessment.

\section{Inter-rater reliability}

The inter-rater reliability $(n=24)$ was excellent for the a-ADL-DI ICC $=.996, \quad(p<.001 ; C I$ 95\%:.991-.998), the a-ADL-CDI ICC=.979 ( $p<.001 ; C I$ 95\%:.952-.991), and a-ADL-PDI ICC $=.975(p<.001 ; C I$ 95\%:.942-.989). No significant difference between raters was observed (a-ADL-DI: rater 1 65; SD 19.4; rater 2 65.9; SD 20.5; a-ADL-CDI: rater 1 : 16.7; SD 14.9; rater 2: 16.6; SD 14.3; a-ADL-PDI: rater 1 : 9.6; SD 8.2; rater 2: 9.6; SD 8.2).

\section{Agreement between patient and proxy}

The overall agreement (a-ADL-DI) between patient and proxy $(n=25)$ showed an ICC $=.908(p<.001 ; C I$ 95\%: .792-.960), for the MCI-group $(n=11)$ ICC $=.825(p<.01: C I$ 95\%: .350-.953) and for the AD-group $(n=14)$ ICC=.839 ( $p<.01 ; C I 95 \%: .498-.948)$. 


\section{Relationships of a-ADL indices with cognitive outcomes}

As shown in table 4, the a-ADL-DI and a-ADL-CDI scores were strongly inter-related. The a-ADL-DI and a-ADL-CDI were significantly strongly related to the cognitive tests scores (MMSE, CamCog); the a-ADL-PDI score was weakly correlated to cognition. There was a significant correlation between the $\mathrm{i}-\mathrm{ADL}$ and the a-ADL-DI and the a-ADL-CDI scores. Correlational analysis for each group separately did not show any significant correlations.

\section{Discussion}

In this study we tested a new a-ADL tool that was designed to be used in a population with mild cognitive disorders. The a-ADL evaluation tool results in a set of indices, based on the TNA and the extent of functional limitations. This technique has the advantage that it takes each subject as his own reference. The main point of interest was whether these indices allow distinction between cognitively healthy persons, patients with MCI and patients with mild AD. The a-ADL-DI showed a significant difference between $M C I$ and $A D$ and a tendency for a difference between the healthy controls and the MCI's. The a-ADL-CDI showed a significant difference between the three groups. The ROC curves, although preliminary due to the relatively small sample size, showed that it is possible to detect differences between healthy controls, persons with MCI and with AD. As expected, the a-ADL-CDI appears to be the more promising index for the identification of patients with MCI in an older population. The sensitivity and specificity of both indices has to be used with caution, but they are promising enough to warrant further research. Since MCI constitutes a heterogeneous group it also remains to be elucidated in a longitudinal study if the indices can predict who remains stable and who will convert to dementia or AD.

We, as well as others, assumed that a mild decline in cognitive capacities is accompanied by a certain decline in complex functioning [9-11]. In this study we found that a-ADL decline, measured by the a-ADL-DI and a-ADL-CDI correlated with cognitive decline as measured by MMSE and CamCog. As expected, the correlation was less pronounced with the physical index (a-ADL-PDI). Although the indices of the tool are based on the underlying nature of the impairment, the frequent coexistence of physical and cognitive disorders in an older population can be a difficulty in identifying the precise origin of the limitations. In order to reflect this clinical reality, activities can be assigned to different indices. Nevertheless, excellent values for the inter-rater ICC (all >.95) for the indices were found, indicating that the qualifiers were well operationalised, the scoring guidelines were clear and the instructions for the raters were sufficient.

Of the 49 a-ADL listed in the tool, 22 concerned the majority of the participants, while only 7 items were relevant for less than $20 \%$ of them. There were no extra, 
unlisted a-ADL reported by our respondents. Nevertheless, the possibility to mention unlisted $a-A D L$, offered by blank fields in the questionnaire, may be useful for subjects with particular interests and anticipates the introduction of new technologies in daily life. Since all participants could rate at least 11 activities (TNA ranging from 11 to 40 ), the a$A D L$ tool can be used in a wide variety of subjects, regardless of gender, educational level or age. Moreover, the questioning was perceived by the participants as agreeable.

The scores for the various a-ADL differed between the diagnostic groups as expected. In general, higher ICF scores were observed in the AD group while mild scores were mainly observed in the healthy control group and MCI group. ICF4 appeared in all the groups because 'not performing at all' was mainly due to environmental factors, which occurred in all the groups equally. This underlines the importance of taking into account the underlying reason of limited performance and the separated indices in this tool. In future research the usefulness of the indices (e.g. the a-ADL-PDI) could be investigated in other populations such as sarcopenia, etc.

The TNA varied between groups, with the cognitively healthy persons mentioning more activities than the MCI patients, who mentioned more activities than those in the $A D$ group. It has been reported that a diminished performance in cognitively demanding activities (e.g. reading books, playing games) is associated with increased risk for MCI [17]. Since here we explicitly asked the subjects if they had performed the activities in the years preceding their problems, our results are somehow surprising. One would, indeed, expect the TNA to be the same in the three groups. A possible explanation might be found in the brain/cognitive reserve theory [35], which states that the cognitive reserve protects against $A D$. Also, engaging in a-ADL could be seen as a marker for a healthy life-style and, therefore, performing a-ADL might have a beneficial influence by delaying the development of cognitive impairments. On the other hand, a potential recall bias might have led to an underestimation of the TNA in some of the patients. Another potential bias could be related to the fact that the data obtained from the healthy control group were all self-reported, whereas the data from the patient groups were also obtained from the proxies. This explanation seems less likely, given the high level of agreement between patients and proxies (ICC values $>.80$ ), which is also in line with results of other studies [14]This could be an important advantage in clinical practice, where a proxy is not always available. Another possible factor of influence on the TNA might have been the higher educational level observed in the healthy control group, which could have had an impact on the number of high-level activities.

We conclude that the scoring system of this new a-ADL tool allows capturing the mild changes in functioning occurring in mild cognitive problems. Taking into account the underlying reasons of functional problems and the weight of these problems, it can 
distinguish normal aging-related decline from that seen in $\mathrm{MCI}$ and $A D$. Functional assessment is of utmost importance in the diagnosis of mild cognitive disorders. At this moment, to our knowledge, there is no other tool allowing reliable evaluation of the a$A D L$. In clinical practice, evaluation of a-ADL is mainly done in a subjective way. Moreover, assessment of high level functioning might constitute an important predictor of conversion towards AD. Future research should address this issue. 


\section{References}

1. Petersen, R.C., Mild cognitive impairment as a diagnostic entity. Journal of internal medicine, 2004. 256(3): p. 183-94.

2. Winblad, B., et al., Mild cognitive impairment--beyond controversies, towards a consensus: report of the International Working Group on Mild Cognitive Impairment. Journal of internal medicine, 2004. 256(3): p. 240-6.

3. Petersen, R.C., Clinical practice. Mild cognitive impairment. The New England journal of medicine, 2011. 364(23): p. 2227-34.

4. Farias, S.T., et al., $\mathrm{MCl}$ is associated with deficits in everyday functioning. Alzheimer disease and associated disorders, 2006. 20(4): p. 217-23.

5. Jefferson, A.L., et al., Characterization of activities of daily living in individuals with mild cognitive impairment. The American journal of geriatric psychiatry : official journal of the American Association for Geriatric Psychiatry, 2008. 16(5): p. 375-83.

6. Mariani, E., R. Monastero, and P. Mecocci, Mild cognitive impairment: a systematic review. Journal of Alzheimer's disease : JAD, 2007. 12(1): p. 23-35.

7. Perneczky, R., et al., Complex activities of daily living in mild cognitive impairment: conceptual and diagnostic issues. Age and ageing, 2006. 35(3): p. 240-5.

8. Reuben, D.B., et al., A hierarchical exercise scale to measure function at the Advanced Activities of Daily Living (AADL) level. Journal of the American Geriatrics Society, 1990. 38(8): p. 855-61.

9. Njegovan, V., et al., The hierarchy of functional loss associated with cognitive decline in older persons. The journals of gerontology. Series A, Biological sciences and medical sciences, 2001. 56(10): p. M638-43.

10. Tuokko, H., C. Morris, and P. Ebert, Mild cognitive impairment and everyday functioning in older adults. Neurocase, 2005. 11(1): p. 40-7.

11. Yeh, Y.C., et al., Functional disability profiles in amnestic mild cognitive impairment. Dementia and geriatric cognitive disorders, 2011. 31(3): p. 225-32.

12. WHO, International Classification of Functioning, Disability and Health, 2001, World Health Organisation: Geneva.

13. Nygard, L., Instrumental activities of daily living: a stepping-stone towards Alzheimer's disease diagnosis in subjects with mild cognitive impairment? Acta neurologica Scandinavica. Supplementum, 2003. 179: p. 42-6.

14. Farias, S.T., D. Mungas, and W. Jagust, Degree of discrepancy between self and otherreported everyday functioning by cognitive status: dementia, mild cognitive impairment, and healthy elders. International journal of geriatric psychiatry, 2005. 20(9): p. 827-34.

15. Farias, S.T., et al., The measurement of everyday cognition (ECog): scale development and psychometric properties. Neuropsychology, 2008. 22(4): p. 531-44.

16. Farias, S.T., et al., Progression of mild cognitive impairment to dementia in clinic- vs community-based cohorts. Archives of neurology, 2009. 66(9): p. 1151-7.

17. Geda, Y.E., et al., Engaging in cognitive activities, aging, and mild cognitive impairment: a population-based study. The Journal of neuropsychiatry and clinical neurosciences, 2011. 23(2): p. 149-54.

18. Pedrosa, H., et al., Functional evaluation distinguishes $\mathrm{MCl}$ patients from healthy elderly people--the ADCS/MCI/ADL scale. The journal of nutrition, health \& aging, 2010. 14(8): $p$. 703-9.

19. Peres, K., et al., Difficulties in instrumental activities of daily living in Mild Cognitive Impairment: Prevalence and impact on outcome. International Psychogeriatrics, 2005. 17: p. 168-169.

20. Peres, K., et al., Restriction in complex activities of daily living in $\mathrm{MCl}$ : impact on outcome. Neurology, 2006. 67(3): p. 461-6. 
21. Freedman, V.A., Adopting the ICF language for studying late-life disability: a field of dreams? J Gerontol A Biol Sci Med Sci, 2009. 64(11): p. 1172-4; discussion 1175-6.

22. Jette, A.M., Toward a common language of disablement. J Gerontol A Biol Sci Med Sci, 2009. 64(11): p. 1165-8.

23. De Vriendt, P., M. Lambert, and T. Mets, Integrating the International Classification of Functioning, Disability and Health (ICF) in the Geriatric Minimum Data Set-25 (GMDS-25) for intervention studies in older people. J Nutr Health Aging, 2009. 13(2): p. 128-34.

24. Diagnostic and Statistical Manual of Mental Disorders. 4th ed. 2000, American Psychiatric Association: Washington DC.

25. McKhann, G., et al., Clinical diagnosis of Alzheimer's disease: report of the NINCDS-ADRDA Work Group under the auspices of Department of Health and Human Services Task Force on Alzheimer's Disease. Neurology, 1984. 34(7): p. 939-44.

26. Mets, T., et al., Assessment of dementia in elderly outpatients: a comparative study of European centers and consensus statement. Arch Gerontol Geriatr, 2000. 30(1): p. 17-24.

27. Folstein, M.F., S.E. Folstein, and P.R. McHugh, "Mini-mental state". A practical method for grading the cognitive state of patients for the clinician. J Psychiatr Res, 1975. 12(3): p. 189-98.

28. Roth, M., et al., CAMDEX. A standardised instrument for the diagnosis of mental disorder in the elderly with special reference to the early detection of dementia. The British journal of psychiatry : the journal of mental science, 1986. 149: p. 698-709.

29. Yesavage, J.A., et al., Development and validation of a geriatric depression screening scale: $a$ preliminary report. Journal of psychiatric research, 1982. 17(1): p. 37-49.

30. Cummings, J.L., et al., The Neuropsychiatric Inventory: comprehensive assessment of psychopathology in dementia. Neurology, 1994. 44(12): p. 2308-14.

31. Katz, S., et al., Studies of Illness in the Aged. The Index of Adl: A Standardized Measure of Biological and Psychosocial Function. JAMA, 1963. 185: p. 914-9.

32. Lawton, M.P. and E.M. Brody, Assessment of older people: self-maintaining and instrumental activities of daily living. The Gerontologist, 1969. 9(3): p. 179-86.

33. Graf, C., The Lawton instrumental activities of daily living scale. Am J Nurs, 2008. 108(4): p. 52-62; quiz 62-3.

34. De Vriendt, P., et al., The process of decline in advanced activities of daily living: a qualitative explorative study in mild cognitive impairment. International psychogeriatrics / IPA, 2012: p. 1-13.

35. Stern, Y., What is cognitive reserve? Theory and research application of the reserve concept. Journal of the International Neuropsychological Society : JINS, 2002. 8(3): p. 448-60. 
Table 1: advanced ADL-clusters with ICF-codes and description, scale items and N ( \%) performing the activity

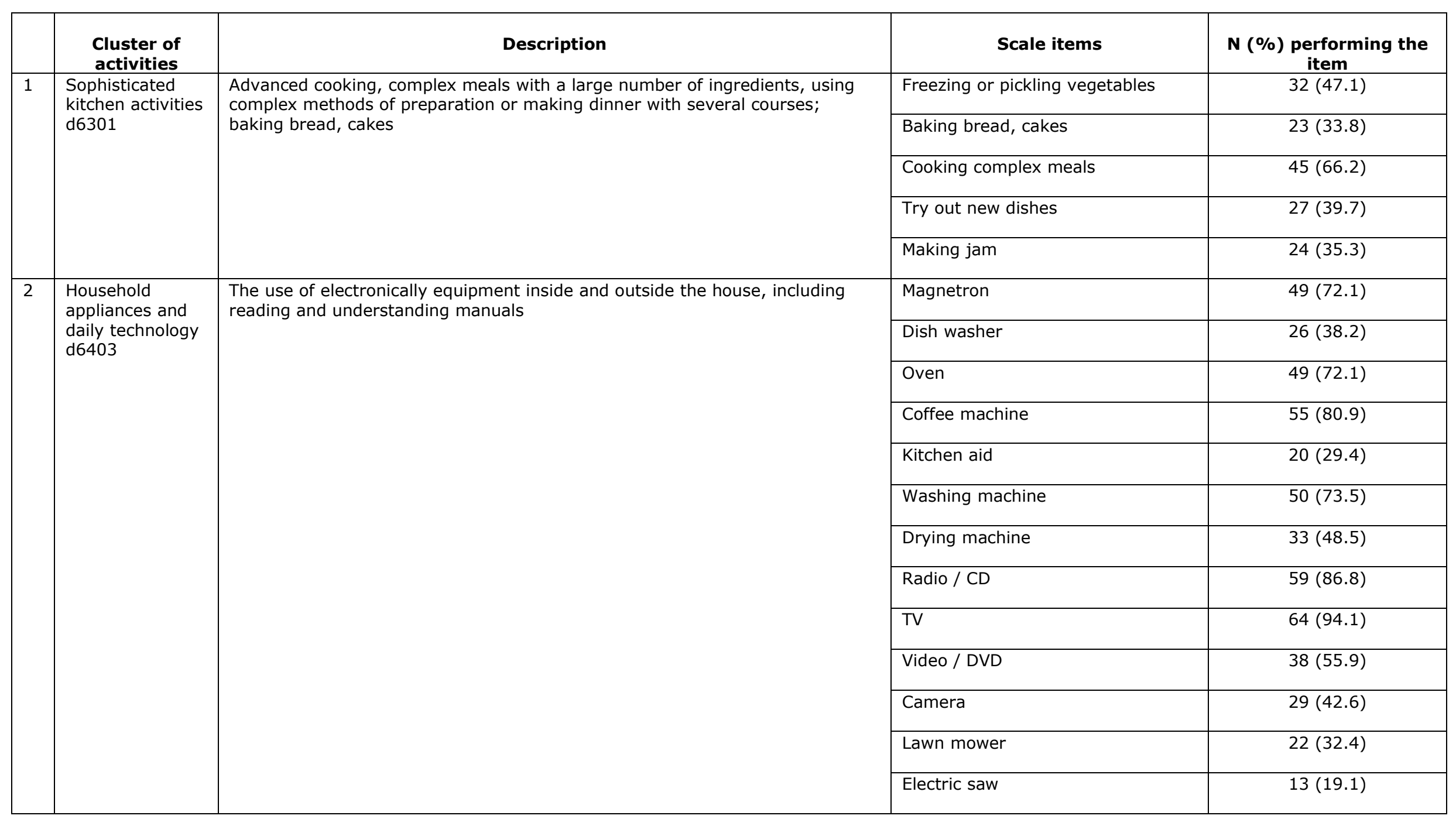




\begin{tabular}{|c|c|c|c|c|}
\hline & & & High pressure cleaner & $9(13.2)$ \\
\hline & & & $\begin{array}{l}\text { Use of manuals explaining daily } \\
\text { technology }\end{array}$ & $61(89.7)$ \\
\hline 3 & $\begin{array}{l}\text { High level } \\
\text { gardening } \\
\text { d6505 }\end{array}$ & To cultivate vegetables and special or rare plants & & $26(38.2)$ \\
\hline \multirow[t]{7}{*}{4} & \multirow{7}{*}{$\begin{array}{l}\text { Cognitive } \\
\text { stimulating } \\
\text { activities or } \\
\text { intellectual } \\
\text { activities } \\
\text { d166 \& d9200 }\end{array}$} & \multirow[t]{7}{*}{$\begin{array}{l}\text { Playing games, reading books, etc...; to read professional literature, books and } \\
\text { magazines in other languages, use of computer programs, use of an agenda }\end{array}$} & Puzzles and brainteasers & $43(63.2)$ \\
\hline & & & PC programs & $17(25)$ \\
\hline & & & Use of internet & $15(22.1)$ \\
\hline & & & Use of agenda & $51(75)$ \\
\hline & & & Reading books & $47(69.1)$ \\
\hline & & & $\begin{array}{l}\text { Reading professional or educational } \\
\text { literature, other languages }\end{array}$ & $14(20.6)$ \\
\hline & & & To write books, poems, articles & $7(10.3)$ \\
\hline \multirow[t]{3}{*}{5} & \multirow{3}{*}{$\begin{array}{l}\text { Craftwork and } \\
\text { arts } \\
\text { d6500 \& d9203 }\end{array}$} & \multirow{3}{*}{$\begin{array}{l}\text { Knitting, sewing, repairing clothes, reattaching buttons and fasteners; } \\
\text { practicing arts like painting, sculpturing and others, playing music instruments }\end{array}$} & Crafts & $25(36.8)$ \\
\hline & & & Playing music instrument & $3(4.4)$ \\
\hline & & & Practicing arts & $8(11.8)$ \\
\hline \multirow[t]{2}{*}{6} & \multirow{2}{*}{$\begin{array}{l}\text { Complex } \\
\text { economic } \\
\text { activities or } \\
\text { transactions } \\
\text { d865 }\end{array}$} & \multirow[t]{2}{*}{$\begin{array}{l}\text { To be involved in some form of complex economic transactions like trading in } \\
\text { commodities, the use of bank cards, 'money out the wall' system, PC-banking }\end{array}$} & $\begin{array}{l}\text { Electronically banking, to pay } \\
\text { electronically, to use money out of } \\
\text { the wall system }\end{array}$ & $60(88.2)$ \\
\hline & & & $\begin{array}{l}\text { Complex administration and } \\
\text { banking }\end{array}$ & $43(63.2)$ \\
\hline \multirow[t]{2}{*}{7} & \multirow{2}{*}{$\begin{array}{l}\text { To communicate } \\
\text { by using devices } \\
\text { or techniques } \\
\text { d360 }\end{array}$} & \multirow[t]{2}{*}{ The use of cell phones, corresponding through email } & Using a cell phone & $52(76.5)$ \\
\hline & & & Writing a mail or a letter & $40(58.8)$ \\
\hline
\end{tabular}




\begin{tabular}{|c|c|c|c|c|}
\hline \multirow[t]{2}{*}{8} & \multirow{2}{*}{$\begin{array}{l}\text { Sports } \\
\text { d9201 }\end{array}$} & \multirow{2}{*}{$\begin{array}{l}\text { To be engage in informal or organized sports: group activities and sporting on } \\
\text { your own, e.g. fishing, ride a bicycle }\end{array}$} & Sports & $18(26.5)$ \\
\hline & & & Riding bicycle & $31(45.6)$ \\
\hline 9 & $\begin{array}{l}\text { Transportation } \\
\text { by motorized } \\
\text { vehicles } \\
\text { d } 475\end{array}$ & To drive a car, motorcycle & & $49(72.1)$ \\
\hline 10 & $\begin{array}{l}\text { Self } \\
\text { development/self } \\
\text { realization/self } \\
\text { educational } \\
\text { activities } \\
\text { d9202 \& d } 810\end{array}$ & $\begin{array}{l}\text { To develop one self by formal or informal learning: attending a course, going } \\
\text { to lectures, consuming arts (visiting exhibitions, musical performances) }\end{array}$ & & $42(61.8)$ \\
\hline 11 & $\begin{array}{l}\text { To go on a } \\
\text { holiday } \\
\text { d920 }\end{array}$ & Going on holiday, in an own cottage or participating in group trips & & $62(91.2)$ \\
\hline \multirow[t]{4}{*}{12} & \multirow[t]{4}{*}{$\begin{array}{l}\text { Caring for or } \\
\text { assisting others } \\
\text { d660 \& d6506 }\end{array}$} & \multirow{4}{*}{$\begin{array}{l}\text { To care for household members (mostly the partner), often by helping to } \\
\text { handle medication, helping with bathing, dressing or assisting in transfers; or } \\
\text { caring for (grand)children and to provide help in household tasks, to take care } \\
\text { of pets, by feeding and cleaning them and exercising them }\end{array}$} & $\begin{array}{l}\text { To help (in the business of) the } \\
\text { children }\end{array}$ & $11(16.2)$ \\
\hline & & & To take care of partner & $7(10.3)$ \\
\hline & & & $\begin{array}{l}\text { To take care of (great) grand } \\
\text { children }\end{array}$ & $27(39.7)$ \\
\hline & & & To take care of pets & $28(41.2)$ \\
\hline 13 & $\begin{array}{l}\text { Caring for } \\
\text { household } \\
\text { objects } \\
\text { d560 }\end{array}$ & $\begin{array}{l}\text { Activities like painting, wallpapering rooms, fixing furniture, plumbing in the } \\
\text { own place or in that of others }\end{array}$ & & $18(26.5)$ \\
\hline 14 & $\begin{array}{l}\text { Semi } \\
\text { professional } \\
\text { work } \\
\text { d855 }\end{array}$ & $\begin{array}{l}\text { To work as a volunteer, engaged in non-remunerative employment and } \\
\text { performing 'semi professional work': social jobs, administration, accountancy, } \\
\text { often as a continuation of ones profession }\end{array}$ & & $24(35.3)$ \\
\hline \multirow[t]{2}{*}{15} & \multirow{2}{*}{$\begin{array}{l}\text { Engagement in } \\
\text { organized social } \\
\text { live or leisure } \\
\text { activities } \\
\text { d910 \& d9250 }\end{array}$} & \multirow{2}{*}{$\begin{array}{l}\text { Active participation in organized communities or societies by taking part in } \\
\text { meetings, being member of the board, organizing activities for others or by } \\
\text { participating in activities organized by others, like short trips and coffee } \\
\text { moments; to be engaged in forms of activity only for amusement or } \\
\text { relaxation, like to go out for diner with partner, children, friends and to visit } \\
\text { family. All activities clustered in this category encompass a social factor by } \\
\text { doing things just for the fun of being together, socializing }\end{array}$} & Organising events & $52(76.5)$ \\
\hline & & & To make and keep appointments & $67(98.5)$ \\
\hline
\end{tabular}




\begin{tabular}{|l|l|l|l|l|}
\hline & & & $\begin{array}{l}\text { To take part in meetings, } \\
\text { conversations }\end{array}$ & $55(80.9)$ \\
\hline & Other & & & \\
\hline
\end{tabular}


Table 2: scoring guidelines for the ICF qualifiers

\begin{tabular}{|l|l|}
\hline ICF-Score & Description \\
\hline $0=$ NO problem & $\begin{array}{l}\text { The activity is carried out completely independently; no help } \\
\text { from others is needed. There are no limitations, the person } \\
\text { carries out the activity in a normal frequency, is adequate, } \\
\text { flexible, inventive and creative (e.g. the person is able to use } \\
\text { all functions of technologic equipment). }\end{array}$ \\
\hline $1=$ MILD problem & $\begin{array}{l}\text { The activity is carried out completely independently; no help } \\
\text { from others is needed but mild limitations are present: less } \\
\text { frequent use, more simplified form of the activity (e.g. only } \\
\text { few functions of technologic equipment). The person needs } \\
\text { more time, is slower, less energetic and has difficulties to } \\
\text { learn something new. The person is less flexible, inventive } \\
\text { and creative, more rigid. }\end{array}$ \\
\hline $2=$ MODERATE problem & $\begin{array}{l}\text { The activity is carried out independently but sometimes help } \\
\text { is needed. There are moderate limitations in performance; } \\
\text { the person is less result oriented, less adequate. There are } \\
\text { faults in performance. }\end{array}$ \\
\hline $3=$ SEVERE problem & $\begin{array}{l}\text { The activity is carried out completely dependently; continuous } \\
\text { help (guiding, support or effective help) from others is } \\
\text { needed. The person experiences severe problems in } \\
\text { performance. }\end{array}$ \\
\hline $4=$ COMPLETE problem & \begin{tabular}{l} 
The person does not perform the activity at all. \\
\hline
\end{tabular} \\
\hline
\end{tabular}


Table 3: Participants' characteristics

\begin{tabular}{|c|c|c|c|}
\hline median (inter quartile) & Healthy control $n=26$ & MCI $\quad n=17$ & AD $n=25$ \\
\hline Age & $79.5(6.0)$ & $77.7(5.4)$ & $82.7(8.8)$ \\
\hline Education in years & $12.0(6.0)$ & $9.0(3.0)^{\mathrm{A} 2}$ & $9.0(3.0)^{\mathrm{B} 2, \mathrm{C} 2}$ \\
\hline Medication & $2.0(2.0)$ & $5.0(4.0)^{\mathrm{A} 3}$ & $6.0(7.0)^{\mathrm{C2}}$ \\
\hline Co morbidities & $2.0(2.5)$ & $4.0(3.0)^{\mathrm{A} 1}$ & $5.0(3.0)^{\mathrm{C} 2}$ \\
\hline MMSE & $29.0(2.0)$ & $27.0(3.5)^{\mathrm{A} 3}$ & $21.0(3.5)^{\mathrm{B} 3, \mathrm{C} 3}$ \\
\hline CamCog & $95.0(6.0)$ & $85.5(9.5)^{\mathrm{A} 3}$ & $73.0(18.5)^{\mathrm{B} 3, \mathrm{C} 3}$ \\
\hline GDS-15 & $2.0(2.0)$ & $2.0(2.0)$ & $3.0(5.0)$ \\
\hline b-ADL & $25.0(0.0)$ & $25.0(4.2)$ & $25.0(8.3)^{\mathrm{C} 1}$ \\
\hline i-ADL & $0.0(4.2)$ & $11.1(15.3)^{\mathrm{A} 3}$ & $25.0(21.5)^{\mathrm{B} 2, \mathrm{C} 3}$ \\
\hline TNA & $30.5(10.0)$ & $24.0(7.0)^{\mathrm{A} 3}$ & $23.0(8.5)^{\mathrm{C3}}$ \\
\hline LA & $12.5(6.0)$ & $14.0(10.0)$ & $17.0(6.5)^{\mathrm{B} 2, \mathrm{C} 2}$ \\
\hline ICFO(\%) & $59.4(13.7)$ & $46.1(37.2)$ & $25.0(19.5)^{\mathrm{B} 3, \mathrm{C} 3}$ \\
\hline LA ICF1(\%) & $50.0(43.6)$ & $\left(23.5(27.5)^{A 1}\right.$ & $14.3(23.5)^{\mathrm{B} 1, \mathrm{C} 3}$ \\
\hline LA ICF2 (\%) & $13.4(14.4)$ & $14.3(14.8)$ & $16.7(24.7)$ \\
\hline LA ICF3(\%) & $0.0(5.5)$ & $0.0(10.4)$ & $14.3(13.4)^{\mathrm{B} 2, \mathrm{C} 3}$ \\
\hline LA ICF4(\%) & $25.0(42.1)$ & $42.8(30.8)$ & $50.0(34.4)$ \\
\hline a-ADL-CDI & $11.5(10.7)$ & $21.6(28.3)^{\mathrm{A} 2}$ & $46.0(22.8)^{\mathrm{B} 2, \mathrm{C} 2}$ \\
\hline a-ADL-PDI & $4.3(5.7)$ & $10.2(11.6)$ & $11.2(15.1)$ \\
\hline
\end{tabular}

MCI: Mild Cognitive Impairment; AD: Alzheimer's disease; MMSE: Mini Mental State Examination; CamCog: Cambridge Examination for mental disorders of the elderly, cognitive part; GDS-15: geriatric depression scale - 15 items; NPI-Q: Neuropsychiatric Inventory Questionnaire; ICF: International Classification of Functioning, Disability and Health score; b-ADL measured by Katz-scale; i-ADL as measured by Lawton-scale; TNA: Total number of activities; LA: Number of limited activities; ICFO(\%): average proportion of activities without limitations; LA ICF1(\%): average proportion of activities with a mild problem; LA ICF2(\%): average proportion of activities with moderate problem; LA ICF3(\%): average proportion of activities with a severe problem: LA ICF4(\%): average proportion of activities with complete problem; a-ADL-DI: advanced Activities of Daily Living-Disability Index ;a-ADL-CDI: advanced Activities of Daily Living-Cognitive Disability Index; a-ADL-PDI: advanced Activities of Daily Living-Physical Disability Index; SD: standard deviation; ${ }^{\dagger}$ lower than normal scores for 1 participant due to a low education level.

Differences between groups tested with Kruskal-Wallis test, group by group tested with Mann-Whitney U test;

Differences between healthy control and MCI: ${ }^{A}$; Differences between MCI and AD: ${ }^{B}$; Differences between healthy control and AD: ${ }^{C}$; Level of

significance ${ }^{1}: p<.05,{ }^{2}: p<.01,{ }^{3}: p<.001$ 
Table 4: correlations between cognitive tests, b-ADL, i-ADL and a-ADL-indices

\begin{tabular}{|l|c|c|c|c|c|c|c|}
\hline & MMSE & CamCog & b-ADL & i-ADL & a-ADL-DI & a-ADL-CDI & a-ADL-PDI \\
\hline MMSE & 1.00 & & & & & & \\
\hline CamCog & $.881^{* *}$ & 1.00 & & & & & \\
\hline B-ADL & $-.305^{*}$ & $-.261^{*}$ & 1.00 & & & & \\
\hline I-ADL & $-.799^{* *}$ & $-.775^{* *}$ & $.504^{* *}$ & 1.00 & & & \\
\hline a-ADL-DI & $-.714^{* *}$ & $-.688^{* *}$ & $.260^{*}$ & $.717^{* *}$ & 1.00 & & \\
\hline a-ADL-CDI & $-.713^{* *}$ & $-.688^{* *}$ & .196 & $.722^{* *}$ & $.888^{* *}$ & 1.00 & \\
\hline a-ADL-PDI & $-.344^{* *}$ & $-.309^{*}$ & .133 & $.303^{*}$ & $.497^{* *}$ & $.349^{* *}$ & 1.00 \\
\hline
\end{tabular}

MMSE: Mini Mental State Examination; CamCog: Cambridge Examination for mental disorders of the elderly, cognitive part; b-ADL: basic activities of daily living measured by Katz-scale; i-ADL: instrumental activities of daily living as measured by Lawton-scale; a-ADL-DI: advanced Activities of Daily Living-Disability Index ; a-ADL-CDI:

advanced Activities of Daily Living-Cognitive Disability Index; a-ADL-PDI: advanced Activities of Daily Living-Physical Disability Index; * Spearman's correlation coefficient $\mathrm{p}<.05 ; * *$ Spearman's correlation coefficient $\mathrm{p}<.01$ 